\title{
Clinical, Biochemical and Molecular Evaluations of Ivermectin Mucoadhesive Nanosuspension Nasal Spray in Reducing Upper Respiratory Symptoms of Mild COVID-19
}

\author{
Zaki F Aref (iD) \\ Shamardan Ezz Eldin S Bazeed (iD) ${ }^{2}$ \\ Mohammed $\mathrm{H} \mathrm{Hassan}^{3}$ \\ Abeer S Hassan (iD) 4 \\ Alaa Rashad ${ }^{5}$ \\ Rehab G Hassan ${ }^{6}$ \\ Aida A Abdelmaksoud' \\ 'ENT Department, Faculty of Medicine, \\ South Valley University, Qena, Egypt; \\ ${ }^{2}$ Tropical Medicine and Gastroenterology \\ Department, Faculty of Medicine, South \\ Valley University, Qena, Egypt; \\ ${ }^{3}$ Department of Medical Biochemistry, \\ Faculty of Medicine, South Valley \\ University, Qena, Egypt; ${ }^{4}$ Department of \\ Pharmaceutics, Faculty of Pharmacy, \\ South Valley University, Qena, Egypt; \\ ${ }^{5}$ Department of Chest Diseases and \\ Tuberculosis, Faculty of Medicine, South \\ Vally University, Qena, Egypt; \\ ${ }^{6}$ Department of Public Health and \\ Community Medicine, Faculty of \\ Medicine, South Valley University, Qena, \\ Egypt
}

Background: Ivermectin is an FDA-approved broad-spectrum anti-parasitic agent that has been shown to inhibit SARS-CoV-2 replication in vitro.

Objective: We aimed to assess the therapeutic efficacy of ivermectin mucoadhesive nanosuspension intranasal spray in treatment of patients with mild COVID-19.

Methods: This clinical trial included 114 patients diagnosed as mild COVID-19. Patients were divided randomly into two age and sex-matched groups; group A comprising 57 patients received ivermectin nanosuspension nasal spray twice daily plus the Egyptian protocol of treatment for mild COVID-19 and group B comprising 57 patients received the Egyptian protocol for mild COVID-19 only. Evaluation of the patients was performed depending on improvement of presenting manifestations, negativity of two consecutive pharyngeal swabs for the COVID-19 nucleic acid via rRT-PCR and assessments of hematological and biochemical parameters in the form of complete blood counts, C-reactive protein, serum ferritin and d-dimer which were performed at presentation and 7 days later.

Results: Of the included patients confirmed with mild COVID-19, 82 were males (71.9\%) and 32 females $(28.1 \%)$ with mean age $45.1 \pm 18.9$. In group A, 54 patients $(94.7 \%)$ achieved 2 consecutive negative PCR nasopharyngeal swabs in comparison to 43 patients (75.4\%) in group $\mathrm{B}$ with $\mathrm{P}=0.004$. The durations of fever, cough, dyspnea and anosmia were significantly shorter in group A than group B, without significant difference regarding the duration of gastrointestinal symptoms. Duration taken for nasopharyngeal swab to be negative was significantly shorter in group A than in group B $(8.3 \pm 2.8$ days versus $12.9 \pm$ 4.3 days; $\mathrm{P}=0.0001)$.

Conclusion: Local use of ivermectin mucoadhesive nanosuspension nasal spray is safe and effective in treatment of patients with mild COVID-19 with rapid viral clearance and shortening the anosmia duration.

Clinicaltrials.gov Identifier: NCT04716569; https://clinicaltrials.gov/ct2/show/ NCT04716569.

Keywords: ivermectin nanosuspension, nasal spray, COVID-19, biochemical and molecular

\section{Introduction}

Correspondence: Mohammed H Hassan Department of Medical Biochemistry, Faculty of Medicine, South Valley University, Qena, 83523, Egypt

Tel +20I098473605

Email mohammedhosnyhassaan@med. svu.edu.eg
Coronaviruses $(\mathrm{CoV})$ include a large number of viruses causing diseases ranging from mild common cold to severe Respiratory Syndrome (MERS-CoV) and Severe Acute Respiratory Syndrome (SARS-CoV). Coronaviruses are zoonotic viruses; SARS-CoV was transmitted from civet cats to humans and MERS-CoV from dromedary camels to 
humans. ${ }^{1}$ The worldwide pandemic of Coronavirus Disease 2019 (COVID-19), is caused by Severe Acute Respiratory Syndrome Coronavirus 2 (SARS-CoV-2), first discovered in Wuhan, China in 2019..$^{2-4}$

Common manifestations of COVID-19 infection include respiratory symptoms, cough, fever, breathing difficulties and anosmia. Severe cases result in pneumonia, severe acute respiratory syndrome, kidney failure and even death. WHO recommendations to prevent infection spread include frequent hand washing, covering nose and mouth when sneezing and coughing, and avoiding close contact with anyone showing symptoms of respiratory symptoms such as coughing and sneezing. ${ }^{1}$

There is currently no specific drug therapy or vaccine available to treat COVID-19. Antimalarial drugs such as hydroxychloroquine and azithromycin, as well as antifilarial drugs such as ivermectin and antiviral drugs such as favipiravir, remdesivir, and umifenovir, have been studied. Many study groups around the world are looking into their potential effectiveness against COVID-19. ${ }^{5}$ Additionally, SARS-CoV and other viral infections are believed to be inhibited by a variety of medicinal plants and natural products such as ilimaquinone (marine sponge metabolite), which have been shown to act on the ACE-2 receptor as well as other viral protein targets. ${ }^{6,7}$ When compared with other cell-based therapies, which may experience challenges such as the cells sticking to the respiratory tract epithelia during administration, mesenchymal stem cells (MSCs) and their exosomes (MSCs-Exo) have shown promise in clinical trials as a therapeutic tool for severely affected COVID-19 patients. $^{8}$

Ivermectin is an FDA-approved broad-spectrum antiparasitic agent that in recent years has shown to have antiviral activity against a broad range of viruses. ${ }^{9,10}$ The mechanism of action of this drug against COVID-19 is unclear, though researchers suggest it works in the same way as it does against other viruses. ${ }^{9}$ It is proved to inhibit integrase protein (IN) nuclear import and HIV-1 replication, ${ }^{11}$ as it inhibits interaction between the importin (IMP) $\alpha / \beta 1$ heterodimer responsible for IN nuclear import and human immunodeficiency virus-1 (HIV-1) integrase protein. ${ }^{11}$ Ivermectin is proved to limit infection caused by some Ribonucleic Acid (RNA) viruses such as West Nile viruses, influenza and dengue virus. ${ }^{12}$ It is reported that ivermectin inhibits the replication of SARSCoV-2 in vitro, and causes reduction about 5000-fold in SARS-CoV-2 viral RNA at 48 hours. ${ }^{13}$ In addition, the binding of the severe acute respiratory syndrome coronavirus 2 (SARS-CoV-2) spike protein to the human cell membrane may be hindered by ivermectin docking. ${ }^{14}$ Nanosuspension is a very fine dispersed drug particle in an aqueous vehicle for either topical and oral use or pulmonary and parenteral administration. ${ }^{15}$ Nanosuspensions have high chemical stability, high drug loading capacity and low toxicity. Intranasal administration needs localization of drug in the nasal cavity for a prolonged time for absorption. ${ }^{16}$ So, nanoparticles must be incorporated into mucoadhesive formulations that maintain the properties of nanosizing simultaneously with localization inside the nasal cavity. ${ }^{17}$

Because olfactory disturbances (anosmia/hyposmia) are frequently presenting manifestations of COVID-19, ${ }^{18}$ and many patients could still have these disturbances for variable times (days to months) after complete cure from SARS-CoV-2, which can significantly affect their psychological status, we studied the local use of ivermectin as a mucoadhesive nanosuspension intranasal spray (where a large viral load is found at the early stages of the infection) to explore its possible effect in curing mild COVID-19 patients, with special concern on assessment of the possible efficacy in curing the olfactory manifestations based on clinical, biochemical and molecular data of the included patients, as previous clinical trials regarding local "nasal" use of ivermectin in humans are limited.

\section{Patients and Methods} Study Design and Participants

This is a prospective clinical trial which included 114 patients diagnosed as mild COVID-19 who presented to the outpatients clinic, Qena University Hospital, Upper Egypt, during the period from February to March, 2021. Ethical approval from the Ethics Committee, Faculty of Medicine South Valley University was taken before starting the study (code: SVU 2021/1/120). Written informed consents were obtained from the included patients regarding the approval to use the drug and performing the required investigations and the study was conducted in accordance with the Declaration of Helsinki. The patients with mild COVID-19 were divided randomly into two groups; group A included 57 patients with mild COVID19 who received ivermectin nanosuspension nasal spray twice daily plus the Egyptian protocol of treatment for COVID-19 and group B included 57 patients with mild COVID-19 who received the Egyptian protocol for COVID-19 only. 
The diagnosis of COVID-19 was based on history of exposure, the presence of respiratory manifestation and/or fever, radiological signs suggestive of COVID-19: ground glass opacity "GGO", changes in total leucocytic count and lymphocytic count (normal or reduced). ${ }^{19}$ All cases were confirmed by real-time PCR test positive for SARSCoV-2 using upper respiratory tract swabs.

Regarding illness severity, severe or critical COVID-19 was diagnosed by the presence of one or more of the following; (1) respiratory rate 30 cycles per minute or more, (2) resting room air oxygen saturation of $93 \%$ or less, (3) $\mathrm{PaO}_{2} / \mathrm{FiO}_{2}$ is $300 \mathrm{mmHg}$ or less, (4) respiratory failure requiring mechanical ventilation, shock, organ dysfunction syndrome and ICU admission. COVID-19 patients who did not meet these specifications yet had a positive COVID-19 nucleic acid test were considered to have a mild disease level. ${ }^{20,21} \mathrm{~A}$ mild case of COVID19 is defined as symptomatic case with lymphopenia or leucopenia with no radiological signs for pneumonia, according to the Egyptian management Protocol for COVID-19. ${ }^{22}$

All patients with severe COVID-19 or patients indicated to receive systemic ivermectin according to the Egyptian management protocol for COVID-19 patients, ${ }^{22}$ were excluded from this study. Also chronic ENT disorders such as chronic sinusitis, nasal allergy, patients using nasal spray preparation, systemic or local use of steroids due to any cause, or allergic to ivermectin were excluded.

The Egyptian protocol for treatment of mild COVID19 includes:

1. Paracetamol $500 \mathrm{mg}$ intravenously every 6 hours.

2. Hydroxychloroquine $500 \mathrm{mg} / 12 \mathrm{~h}$ with close monitoring of liver and kidney functions.

3. Azithromycin $1 \mathrm{~g}$ first day, then $500 \mathrm{mg}$ per day for 3 days or clarithromycin $500 \mathrm{mg}$ every 12 hfor $7-14$ days.

4. Oseltamivir $150 \mathrm{mg} / 12 \mathrm{~h}$ for 5 days.

5. Ascorbic acid $500 \mathrm{mg} / 12 \mathrm{~h}$.

6. Cyanocobalamin IV once daily.

\section{Data Collection}

Demographic data were recorded for all patients including age, sex, BMI, comorbidities, and smoking, clinical manifestations including fever, cough, dyspnea, anosmia and gastrointestinal tract (GIT) symptoms such as diarrhea, vomiting and/or abdominal pain. Full laboratory investigations were done in all patients and chest CT performed.
Follow-up of all included patients until complete recovery from COVID-19 and the recovery durations of all symptoms for all included patients were recorded in days. Follow up of routine laboratory tests was conducted 7 days after starting ivermectin nanosuspension nasal spray. Group A patients were followed also for any side effects of the ivermectin nanosuspension nasal spray.

\section{Hematological, Biochemical and Molecular Measurements}

(A) $6 \mathrm{ml}$ of venous blood was withdrawn from every included patient prior to therapy and was divided into 3 parts $(2 \mathrm{ml}$ were evacuated into EDTA tubes for $\mathrm{CBCs} ; 2 \mathrm{ml}$ were evacuated into serum gel separator tubes and allowed to be clotted at $37^{\circ} \mathrm{C}$ for $30 \mathrm{~min}$ and then centrifuged $3500 \mathrm{rpm}$ for 10 minand the separated sera were used for C-reactive protein (CRP) and ferritin assays, while the remaining $2 \mathrm{ml}$ were adjusted to be evacuated into citrate tubes and after centrifugation the separated citrated plasma was used for D- dimer assays) as follows:

1. $\mathrm{CBC}$ with differential: By using cell Dyne-Ruby (Abbott Diagnostics,Santa Clara, CA,USA), automated cell counter.

2. Determination of D-dimer: By automated blood coagulation analyzer CS-1600, Japan. The assay kit was supplied by Spectrum, Egyptian company of biotechnology, Cairo, Egypt, catalogue No. 585002. The assay is based upon reinforced immunoturbidimetry monoclonal anti D-dimer antibodies in the reagent react with the $\mathrm{D}$-dimer antigen in the sample, forming antigen/antibody complexes that increase the work solution turbidity.

3. CRP (C-reactive protein): Assays were performed using the semi-quantitative latex agglutination test (AVITEX CRP kits; Catalog No. OD023; supplied by Omega Diagnostics, UK).

4. Serum ferritin assays were performed using commercially available ELISA assay kits (supplied by BIOCHECK Inc., Foster City, CA, USA, catalog number: BC-1025), by an ELISA multiskan EX microplate photometer, Thermo Scientific (STAT FAX-2100, USA) according to the manufacturer's protocol.

(B) PCR testing was performed on aliquots of Universal Transport Medium (UTM) used for 
nasopharyngeal swabs collection (Huachenyang Technology, China). Aliquots were extracted on the QIA symphony platform (QIAGEN, USA) and tested with real-time reverse-transcription PCR (RT-qPCR) using the QIAamp ${ }^{\circledR}$ DSP Virus Spin Kit (QIAGEN Hilden, Germany) on a Rotor-Gene Q (QIAGEN Hilden, Germany). ${ }^{18}$ PCR was repeated at day 5 and every $48 \mathrm{~h}$ thereafter until 2 consecutive negative PCR were obtained.

\section{Ivermectin Nanosuspension Materials}

Poloxamer 407 and Poloxamer 188 were obtained from Sigma Chemicals Co. (St. Louis, MO, USA). Sodium alginate was supplied by General Chemical and Pharmaceutical Co. Ltd, Sudbury, UK. Hydroxypropyl methylcellulose 15,000 (HPMC) was obtained from ElGomhouria Co., Cairo, Egypt. Carbopol 974P (CP) was obtained from Lubrizol Co., Cleveland, OH, USA.

\section{Preparation of Ivermectin Nanosuspension}

Ivermectin nanosuspension was developed using a nanoprecipitation method followed by ultrasonication as reported in the literature. ${ }^{23}$ A specified amount of ivermectin was dissolved in a small amount of acetone to form the solvent phase $(120 \mathrm{mg} / \mathrm{L})$. Poloxamer 407 and Poloxamer 188 as stabilizers were dissolved in distilled water at concentrations of 2 and $1 \% \mathrm{w} / \mathrm{v}$, respectively to form antisolvent phase. The drug solution was then added dropwise to the aqueous stabilizer solution using a suitable syringe under continuous stirring on magnetic stirrer at $25^{\circ}$ C (3000 rpm for $30 \mathrm{~min})$. The resultant homogenous suspension was immediately subjected to ultrasonication using a probe-type sonicator (Cole-Parmer, Vernon Hills, IL, USA) for $10 \mathrm{~min}$ at 5 spauses and amplitude pressure $50 \%$ for further control of particle aggregation. After sonication, the nanosuspension was placed on a magnetic stirrer for $2 \mathrm{~h}$ to ensure the complete evaporation of solvent.

\section{Preparation of Mucoadhesive Nasal Spray Containing Ivermectin Nanosuspension}

For the preparation of the mucoadhesive nasal formulation of ivermectin nanosuspension, mucoadhesive polymer mixture (HPMC K15M $(0.3 \% \mathrm{w} / \mathrm{v})$, Carbopol 974P $(0.1 \% \mathrm{w} / \mathrm{v})$ and sodium alginate $(0.2 \% \mathrm{w} / \mathrm{v}))$ were added to the prepared nanosuspension with continuous stirring until an homogenous viscous dispersion was obtained. To this formulation other ingredients such as sodium benzoate
$(0.01 \% \mathrm{w} / \mathrm{v})$ and glycerol $(1.0 \% \mathrm{w} / \mathrm{v})$ as preservatives were added and mixed well. Finally, the prepared formulation was filled into nasal spray containers. Concentration of ivermectin per puff was $70 \mu \mathrm{g} / \mathrm{mL}$.

\section{Therapeutic Efficacy Points}

The judging points regarding the efficacy of Ivermectin nanosuspension nasal spray in improving patients with mild COVID-19 were as follows (Figure 1):

1. Clinical improvements of the presenting manifestations with recording the recovery duration for every manifestation.

2. Two consecutive pharyngeal swabs were negative for COVID-19 nucleic acid via rRT-PCR, and the time between them, up to $72 \mathrm{~h}$.

3. Improvement of the abnormal routine laboratory parameters (CBCs with differential, CRP, ESR, ferritin, d-dimer) 7 days after starting treatment.

\section{Statistical Analysis}

Data entry and data analysis were done using SPSS version 26 (Statistical Package for Social Science). Data were presented as a number, percentage, the mean and standard deviation for parametric data, the median and inter-quartile range for non-parametric data. Chi-square test and Fisher exact test were used to compare qualitative variables. MannWhitney test was used to compare between two quantitative variables and Kruskal-Wallis test was used to compare between more than two quantitative variables for nonparametric data. Independent $t$-test was used to compare between two quantitative variables for parametric data. $\mathrm{P}$-value was considered statistically significant when $<0.05$.

\section{Results}

\section{Demographic Data of Study Groups}

This prospective study included 114 patients with mild COVID-19; 82 males (71.9\%) and 32 females (28.1\%) with mean age $45.1 \pm 18.9$. All patients showed no signs suggestive of moderate or severe COVID-19 on CT chest. Co-morbidities were present in 47 patients of all patients (41.2\%) in the form of chronic obstructive pulmonary disease [ 1 case $(0.9 \%)]$, cerebrovascular stroke [ 4 cases (3.5\%)], diabetes mellitus [14 cases $(12.3 \%)]$, hypertension [20 cases (17.5\%)], bronchial asthma and interstitial pulmonary fibrosis [3 cases for each, (2.7\%)]. Both groups were age and sex matched. Group A (ivermectin 


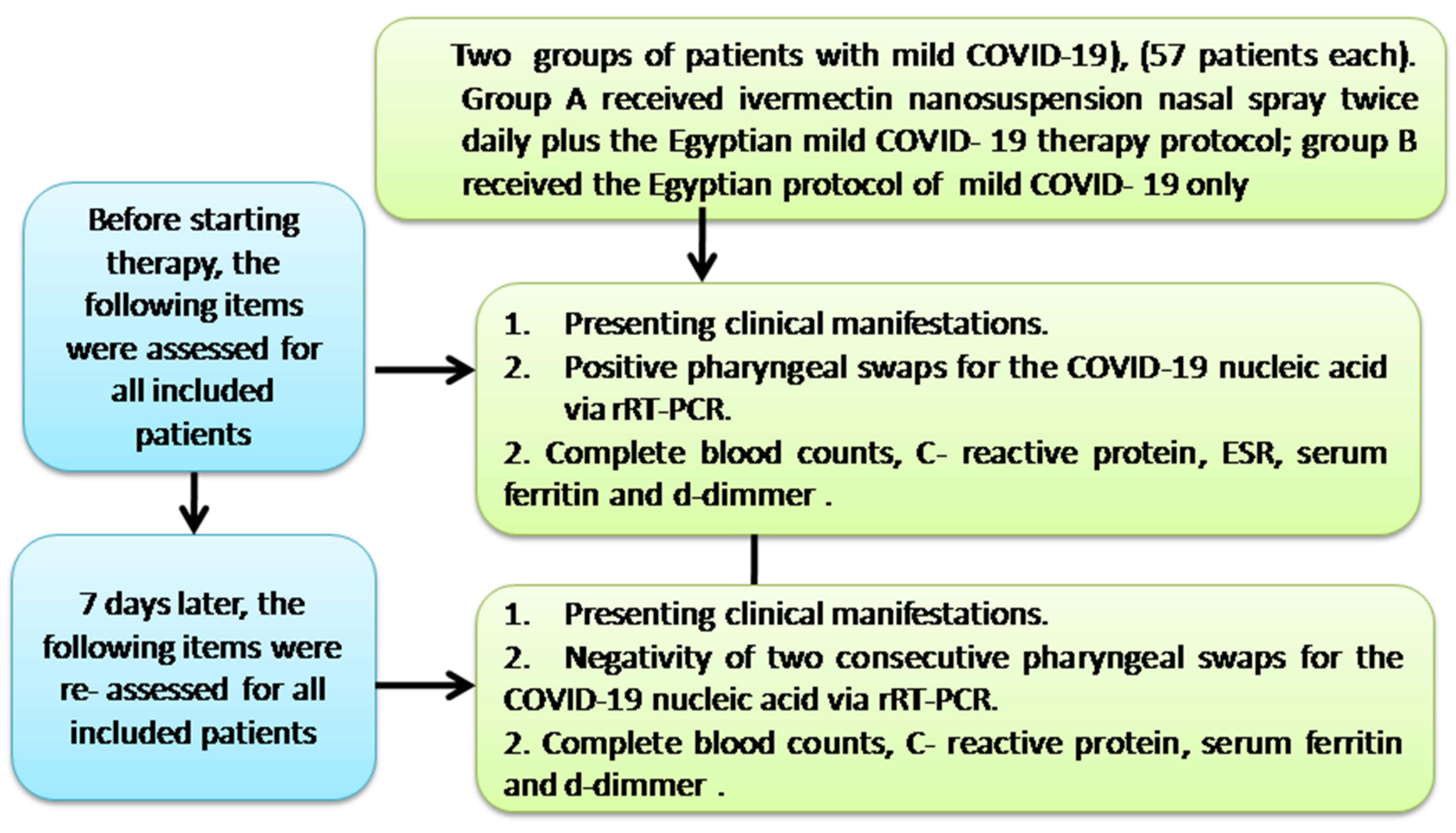

Figure I Flow chart of the study design.

nanosuspension nasal spray treated group) included 40 males (70.2\%) and 17 females (29.8\%) and group B included 42 males $(73.7 \%)$ and 15 females $(26.3 \%)$ with no significant difference $(\mathrm{P}=0.7)$. The mean age (years) of group $\mathrm{A}$ is 44.8 \pm 19.2 versus $45.5 \pm 18.8$ in group $B$, with no significant difference $(\mathrm{P}=0.8)$. Neutrophil/lymphocyte ratio before treatment was $3.1 \pm 1.3$ in group A versus $3.1 \pm 1.2$ in group B with $\mathrm{P}=0.9$. Also the median values of CRP, D-dimer, and serum ferritin were not significantly different between the two study groups ( $\mathrm{P}=0.9,0.5$, and 0.7 respectively). There were no significant differences regarding the history of contact cases which was found in 30 patients of group A (52.6\%) versus 28 patients of group B (49.1\%) with $\mathrm{P}=0$ 0.7. As regards the frequency of different blood groups, there were no statistically significant differences between both groups, $\mathrm{P}=0.9$ (Table 1). There was no statistical significant difference between both groups regarding frequency of cough, dyspnea, anosmia, and GIT symptoms, as shown in Table 1.

\section{Response to Ivermectin Mucoadhesive Nanosuspension Nasal Spray}

In the ivermectin-treated group (group A) 54 patients (94.7\%) achieved 2 consecutive negative PCR nasopharyngeal swabs in comparison to 43 patients $(75.4 \%)$ in the control group, $\mathrm{P}=0.004$, as shown in Table 2. Patients who progressed to more severe disease were only $3(5.3 \%)$ cases in the ivermectin-treated group and $14(24.6 \%)$ cases in group B. No side effects were recorded in the ivermectin nanosuspension nasal spray treated group.

The durations (days) of fever, cough, dyspnea, anosmia, and GIT manifestations were assessed in the improved patients in both groups. Ivermectin-treated group (group A) exhibited significantly shorter mean duration of fever, cough, dyspnea, and anosmia compared with group B: $5 \pm 1.7$ days versus $13.6 \pm 2.7$ days; $5 \pm 1.9$ days versus $14 \pm 2.6 ; 4.4 \pm 2.7$ days versus $10.1 \pm 3.4 ; 0.5 \pm 0.9$ versus $1.6 \pm 3.2$, respectively with $\mathrm{P}=0.0001$ for all (Table 3). As regards gastrointestinal symptoms duration there was no significant difference between both groups, $\mathrm{P}=0.884$, as shown in Table 3 . In this study no patients in both groups showed persistent anosmia or gastrointestinal manifestation, even those who failed to achieve negative PCR.

Mean duration taken for nasopharyngeal swab to be negative was significantly shorter in group A than in group $\mathrm{B}(8.3 \pm 2.8$ days versus $12.9 \pm 4.3$ days; $\mathrm{P}=0.004)$ (Table 3).

All laboratory parameters [neutrophil/lymphocyte ratio, CRP (mg/dl), D-dimer (ng/mL), and ferritin (ng/ 
Table I Comparison Between Demographic Data of Both Study Groups

\begin{tabular}{|c|c|c|c|c|}
\hline \multicolumn{2}{|l|}{ Variables } & $\begin{array}{l}\text { Ivermectin-Treated Group } \\
(n=57)\end{array}$ & $\begin{array}{l}\text { Control Group } \\
(n=57)\end{array}$ & P-value \\
\hline \multicolumn{2}{|l|}{ Age (years, mean $\pm S D$ ) } & $44.8 \pm 19.2$ & $45.5 \pm 18.8$ & 0.8 \\
\hline Sex (No., \%) & $\begin{array}{l}\text { Male } \\
\text { Female }\end{array}$ & $\begin{array}{l}40(70.2 \%) \\
17(29.8 \%)\end{array}$ & $\begin{array}{l}42(73.7 \%) \\
15(26.3 \%)\end{array}$ & 0.7 \\
\hline \multicolumn{2}{|c|}{ Body Mass Index $\left(\mathrm{kg} / \mathrm{m}^{2}\right.$, mean $\left.\pm \mathrm{SD}\right)$} & $26.9 \pm 3.5$ & $28.1 \pm 4.9$ & 0.1 \\
\hline \multirow{3}{*}{\multicolumn{2}{|c|}{$\begin{array}{l}\text { Smoking (No., \%) } \\
\text { •Yes } \\
\text { •No }\end{array}$}} & & & \\
\hline & & 19(33.3\%) & $25(43.9 \%)$ & 0.2 \\
\hline & & $38(66.7 \%)$ & $32(56.1 \%)$ & \\
\hline \multicolumn{2}{|c|}{ Neutrophil/lymphocyte ratio before treatment (mean \pm SD) } & $3.1 \pm 1.3$ & $3.1 \pm 1.2$ & 0.9 \\
\hline \multicolumn{2}{|c|}{ CRP (mg/dl, median and inter-quartile range) } & $\begin{array}{l}14 \\
(0.25-80)\end{array}$ & $\begin{array}{l}15 \\
(0.25-82)\end{array}$ & 0.9 \\
\hline \multicolumn{2}{|c|}{ D dimer ( $\mathrm{ng} / \mathrm{mL}$, median and inter-quartile range) } & $\begin{array}{l}320 \\
(100-850)\end{array}$ & $\begin{array}{l}300 \\
(100-1000)\end{array}$ & 0.5 \\
\hline \multicolumn{2}{|c|}{ Ferritin ( $\mathrm{ng} / \mathrm{mL}$, median and inter-quartile range) } & $\begin{array}{l}689 \\
(75-2009)\end{array}$ & $\begin{array}{l}630 \\
(75-2009)\end{array}$ & 0.7 \\
\hline Contact cases (No., \%) & $\begin{array}{l}\text { Yes } \\
\text { No }\end{array}$ & $\begin{array}{l}30(52.6 \%) \\
27(47.4 \%)\end{array}$ & $\begin{array}{l}28(49.1 \%) \\
29(50.9 \%)\end{array}$ & 0.7 \\
\hline Blood groups (No., \%) & $\begin{array}{l}A \\
A B \\
B \\
0\end{array}$ & $\begin{array}{l}17(29.8 \%) \\
14(24.6 \%) \\
9(15.8 \%) \\
17(29.8 \%)\end{array}$ & $\begin{array}{l}18(31.6 \%) \\
14(24.6 \%) \\
9(15.8 \%) \\
16(28.1 \%)\end{array}$ & 0.9 \\
\hline Cough (No., \%) & $\begin{array}{l}\text { Yes } \\
\text { No }\end{array}$ & $\begin{array}{l}56(98.2 \%) \\
\mathrm{I}(\mathrm{I} .8 \%)\end{array}$ & $\begin{array}{l}57(100 \%) \\
0(0 \%)\end{array}$ & 0.3 \\
\hline Dyspnea (No., \%) & $\begin{array}{l}\text { Yes } \\
\text { No }\end{array}$ & $\begin{array}{l}50(87.7 \%) \\
7(12.5 \%)\end{array}$ & $\begin{array}{l}54(94.7 \%) \\
3(5.3 \%)\end{array}$ & 0.2 \\
\hline Anosmia (No., \%) & $\begin{array}{l}\text { Yes } \\
\text { No }\end{array}$ & $\begin{array}{l}13(22.8 \%) \\
44(77.2 \%)\end{array}$ & $\begin{array}{l}\mid 4(24.6 \%) \\
43(75.4 \%)\end{array}$ & 0.8 \\
\hline GIT symptoms (No., \%) & $\begin{array}{l}\text { Yes } \\
\text { No }\end{array}$ & $\begin{array}{l}23(40.4 \%) \\
34(59.6 \%)\end{array}$ & $\begin{array}{l}22(38.6 \%) \\
35(61.4 \%)\end{array}$ & 0.8 \\
\hline
\end{tabular}

$\mathrm{mL})$ ] of both groups showed reduction towards normality references 7 days after diagnosis with more significant reduction in group A compared with group B. The median values and inter-quartile ranges in group $A$ versus group B were $[1.5(0.5-3.5)$ versus $1.9(0.6-4.2) ; 6$ (3-96) versus 15 (2-120); 250 (100-900) versus 310 (10-900); 199 (76$2020)$ versus 253 (75-2100) respectively] (Table 4).

\section{Discussion}

There is no definite drug therapy for COVID-19 up till now. Several drugs are under clinical trials for treatment of this serious disease, Ivermectin is one of these drugs. ${ }^{10,24}$ Ivermectin previously has been used in treatment of lymphatic filariasis, and Onchocerca volvulus. ${ }^{2}$ It is proved to have antiviral activity against a number of viruses in in vitro investigations ${ }^{3,25-27}$ and is also found to limit viral infections such as influenza, West Nile viruses, and dengue fever. An in vitro study reported that ivermectin inhibits SARSCoV-2, with a single addition to Vero/hSLAM cells 2-h post infection and reduces viral RNA $\sim 5000$ - at 48 h. ${ }^{2,3,10,11,26,27}$ Recent studies that examined the efficacy of ivermectin have shown antiviral activity for many viral infections. ${ }^{28}$ 
Table 2 COVID-19 PCR Negative Conversion Achievement in Ivermectin and Control Group

\begin{tabular}{|l|l|l|l|}
\hline $\begin{array}{l}\text { PCR Negative } \\
\text { Conversion }\end{array}$ & $\begin{array}{c}|c| \\
\text { Ivermectin } \\
\text { Treated Group } \\
(\mathbf{n = 5 7 )}\end{array}$ & $\begin{array}{c}\text { Control } \\
\text { Group } \\
(\mathbf{n = 5 7 )}\end{array}$ & P-value \\
\hline Yes & $54(94.7 \%)$ & $43(75.4 \%)$ & $0.004^{*}$ \\
No & $3(5.3 \%)$ & $14(24.6 \%)$ & \\
\hline
\end{tabular}

Note: * Significant at $\mathrm{P}<0.05$.

Caly et al. found that a single dose of $5 \mu \mathrm{M}$ ivermectin can inhibit SARS-CoV-2 in vitro with $99.98 \%$ reduction of viral RNA in $48 \mathrm{~h}^{10}$ The FDA-approved dose of ivermectin for other diseases is $150-200 \mathrm{mcg} / \mathrm{kg}$. But Caly et al. used a single large dose 30 times greater than the FDA-approved one. ${ }^{6}$ This study showed that mean age of mild COVID-19 patients is $45.1 \pm 18.9$ years, which is in agreement with Ghweil et al., who reported that severe COVID-19 was more frequent in older age groups, while mild to moderate infection was more frequent in younger age groups; ${ }^{29}$ this is also reported by other investigators. ${ }^{30-34}$

In this study the most common comorbidities were diabetes mellitus and hypertension which is similar to results reported by Ghweil et al. ${ }^{29}$ Astudy done by Marhl et al. reported that a higher risk for COVID-19 among diabetic patients may be due to associated dysregulation of angiotensin-converting enzyme 2 (ACE2), liver dysfunction, and chronic inflammation; ${ }^{35}$ Singh et al. reported the same results. ${ }^{36}$ In a randomized trial done by Shouman et al., ivermectin was used as a chemoprophylactic agent

Table 3 Comparison Between Both Groups as Regards Duration of Fever, Cough, Dyspnea, Anosmia, GIT Symptoms and Duration to PCR Negative Conversion

\begin{tabular}{|c|c|c|c|}
\hline Duration (Days) & $\begin{array}{l}\text { Ivermectin- } \\
\text { Treated } \\
\text { Group } \\
(n=57)\end{array}$ & $\begin{array}{c}\text { Control } \\
\text { Group } \\
(n=57)\end{array}$ & P-value \\
\hline Fever $($ mean $\pm S D)$ & $5 \pm 1.7$ & $13.6 \pm 2.7$ & $0.0001 *$ \\
\hline Cough (mean $\pm \mathrm{SD}$ ) & $5 \pm 1.9$ & $14 \pm 2.6$ & $0.0001 *$ \\
\hline Dyspnea (mean \pm SD) & $4.4 \pm 2.7$ & $10.1 \pm 3.4$ & $0.0001 *$ \\
\hline Anosmia (mean $\pm S D)$ & $2 \pm 0.8$ & $6.4 \pm 3.3$ & $0.0001 *$ \\
\hline $\begin{array}{l}\text { GIT symptoms (median } \\
\text { and inter-quartile range) }\end{array}$ & $\begin{array}{c}5 \\
(I-9)\end{array}$ & $\begin{array}{c}4 \\
(I-9)\end{array}$ & 0.884 \\
\hline $\begin{array}{l}\text { PCR negative } \\
\text { conversion (mean } \pm S D \text { ) }\end{array}$ & $8.3 \pm 2.8$ & $12.9 \pm 4.3$ & $0.0001 *$ \\
\hline
\end{tabular}

Note: *Significant at $\mathrm{P}<0.05$. for contacts of COVID-19 patients and they found that ivermectin is a safe and effective chemoprophylactic agent in prevention of COVID-19. ${ }^{37}$

A randomized, double-blind trial was done in Dhaka, Bangladesh in which oral ivermectin alone $(12 \mathrm{mg}$ once daily for 5 days) or in combination with doxycycline (12 $\mathrm{mg}$ ivermectin single dose and $200 \mathrm{mg}$ doxycycline day-1 followed by $100 \mathrm{mg}$ 12-hourly for next 4 days) was compared with placebo among patients with COVID-19 infection. Negative PCR was earlier in the 5-day ivermectin treatment group versus the placebo. ${ }^{38}$ A recent study done in Florida, USA, reported that COVID-19 patients given ivermectin with other treatments (e.g., azithromycin and hydroxychloroquine) showed lower mortality rate than COVID-19 patients who did not receive ivermectin. ${ }^{39}$

Various studies have reported the nasal delivery of nanosuspensions. Saindane et al. incorporated a carvedilolcontaining nanosuspension into in situ gel, ${ }^{40}$ and Alshweiat et al. prepared a loratadine-based nasal nanosuspension to improve bioavailability. ${ }^{12}$ SARS-CoV-2 invades the oropharynx and nasopharynx, from which it transmits even before any signs appear. The first symptoms (odynophagia, anosmia, dry cough, fever) and lung parenchyma colonization occur when the virus replicates in this region. The use of a nasal ivermectin spray to deposit the drug in the upper respiratory tract may be a useful method for exposing the SARS-CoV-2 virus (or the cells that contain the viral particles) to high ivermectin concentrations. As a result, early in the infection, the viral load is reduced, preventing extensive viral replication, transmission, and disease aggravation. ${ }^{41}$

No previous study has used ivermectin in a nanosuspension nasal spray. In this study we tried to decrease the viral load in the nose and nasopharynx in early COVID 19 patients by the direct action of an ivermectin nanosuspension nasal spray. Administration of nanosuspension by nasal spray provides uniform distribution of the drug through the nasal mucosa. Mucoadhesive polymers such as hydroxypropyl methylcellulose 15,000 (HPMC K15M), carbopol 974P and sodium alginate were used in a mixture to increase the residence time of formulation at site of action. ${ }^{12,13}$

In this study, COVID-19 patients treated with an ivermectin mucoadhesive nanosuspension nasal spray showed shorter duration of fever, dyspnea, cough, and anosmia but not GIT symptoms duration. Additionally, the findings of the current study revealed that patients with COVID-19 treated with ivermectin showed more 
Table 4 Comparison Between Both Groups as Regard Laboratory Parameters Changes 7 Days After Diagnosis

\begin{tabular}{|c|c|c|c|}
\hline Variables & $\begin{array}{l}\text { Ivermectin Treated Group } \\
\qquad(\mathrm{n}=57)\end{array}$ & $\begin{array}{l}\text { Control Group } \\
\qquad(n=57)\end{array}$ & P-value \\
\hline Neutrophil/lymphocyte ratio (median and inter-quartile range) & $\begin{array}{c}1.5 \\
(0.5-3.5)\end{array}$ & $\begin{array}{c}1.9 \\
(0.6-4.2)\end{array}$ & $0.008^{*}$ \\
\hline CRP (mg/dl, median and inter-quartile range) & $\begin{array}{c}6 \\
(3-96)\end{array}$ & $\begin{array}{c}15 \\
(2-120)\end{array}$ & $0.000 I^{*}$ \\
\hline D dimer ( $\mathrm{ng} / \mathrm{mL}$, median and inter-quartile range) & $\begin{array}{c}250 \\
(100-900)\end{array}$ & $\begin{array}{c}310 \\
(10-900)\end{array}$ & $0.03 *$ \\
\hline Ferritin ( $\mathrm{ng} / \mathrm{mL}$, median and inter-quartile range) & $\begin{array}{c}199 \\
(76-2020)\end{array}$ & $\begin{array}{c}253 \\
(75-2100)\end{array}$ & $0.004 *$ \\
\hline
\end{tabular}

Note: *Significant at $\mathrm{P}<0.05$.

significant reduction in measured hematological and biochemical parameters towards normal values with rapid viral clearance as evidenced by conversion of nasopharyngeal swab to negative. Further studies should be done to assess the ivermectin nanosuspension nasal spray in prophylaxis of close contacts to COVID-19 patients.

\section{Conclusion}

Local use of ivermectin mucoadhesive nanosuspension nasal spray is safe and effective in treatment of mild COVID-19 patients, with rapid viral clearance and recovery of respiratory manifestations (anosmia, cough, and dyspnea). The result of efficacy of ivermectin in reducing patients' symptoms can promote the current protocols of COVID-19 treatment. Further studies should be done to assess the possible role of ivermectin mucoadhesive nanosuspension nasal spray as a prophylaxis against COVID19 infection.

\section{Study Limitations}

The current study's main limitation was the lack of a multi-dose design of ivermectin to assess the potential dose-effect relationship, which could be designed in future studies.

\section{Data Sharing Statement}

The datasets used and/or analyzed during the current study are available from the corresponding author on reasonable request.

\section{Funding}

This research was partially funded by South Valley University, Faculty of Medicine, Qena 83523, Egypt.

\section{Disclosure}

No potential conflicts of interest between authors to be declare.

\section{References}

1. El-Sayed, A., Kamel, M. Coronaviruses in humans and animals: the role of bats in viral evolution. Environ Sci Pollut Res. 2021;28:19589-19600. doi:10.1007/s11356-021-12553-1

2. González Canga A, Sahagún Prieto AM, Diez Liébana MJ, et al. The pharmacokinetics and interactions of ivermectin in humans-a minireview. AAPS J. 2008;10(1):42-46. doi:10.1208/s12248-007-9000-9

3. Götz V, Magar L, Dornfeld D, et al. Influenza A viruses escape from MxA restriction at the expense of efficient nuclear vRNP import. Sci Rep. 2016;6:23138. doi:10.1038/srep23138

4. Wagstaff KM, Sivakumaran H, Heaton SM, Harrich D, Jans DA. Ivermectin is a specific inhibitor of importin $\alpha / \beta$-mediated nuclear import able to inhibit replication of HIV-1 and dengue virus. Biochem J. 2012;443(3):851-856. doi:10.1042/BJ20120150

5. Siddiqui AJ, Jahan S, Ashraf SA, et al. Current status and strategic possibilities on potential use of combinational drug therapy against COVID-19 caused by SARS-CoV-2. J Biomol Struct Dyn. 2020;1-14. doi:10.1080/07391102.2020.1802345

6. Siddiqui AJ, Danciu C, Ashraf SA, et al. Plants-derived biomolecules as potent antiviral phytomedicines: new insights on ethnobotanical evidences against coronaviruses. Plants. 2020;9(9):1244. doi:10.3390/plants9091244

7. Surti M, Patel M, Adnan M, et al. Ilimaquinone (marine sponge metabolite) as a novel inhibitor of SARS-CoV-2 key target proteins in comparison with suggested COVID-19 drugs: designing, docking and molecular dynamics simulation study. RSC Adv. 2020;10 (62):37707-37720. doi:10.1039/D0RA06379G

8. Alzahrani FA, Saadeldin IM, Ahmad A, et al. The potential use of mesenchymal stem cells and their derived exosomes as immunomodulatory agents for COVID-19 patients. Stem Cells Int. 2020;2020:8835986. doi:10.1155/2020/8835986

9. Wagstaff KM, Rawlinson SM, Hearps AC, Jans DA. An AlphaScreen ${ }^{\mathbb{B}}$-based assay for high-throughput screening for specific inhibitors of nuclear import. J Biomol Screen. 2011;16(2):192-200. doi:10.1177/1087057110390360

10. Caly L, Druce JD, Catton MG, Jans DA, Wagstaff KM. The FDA-approved]drug ivermectin inhibits the replication of SARS-CoV-2 invitro. Antiviral Res. 2020;178:104787. doi:10.1016/ j.antiviral.2020.104787 
11. Ketkar H, Yang L, Wormser GP, Wang P. Lack of efficacy of ivermectin for prevention of a lethal Zika virus infection in a murine system. Diagn Microbiol Infect Dis. 2019;95(1):38-40. doi:10.1016/j. diagmicrobio.2019.03.012

12. Alshweiat A, Csóka I, Tömösi F, et al. Nasal delivery of nanosuspension-based mucoadhesive formulation with improved bioavailability of loratadine: preparation, characterization, and in vivo evaluation. Int $J$ Pharm. 2020;579:119166. doi:10.1016/j. ijpharm.2020.119166

13. Alshweiat A, Ambrus R, Csoka I. Intranasal nanoparticulate systems as alternative route of drug delivery. Curr Med Chem. 2019;26 (35):6459-6492. doi:10.2174/0929867326666190827151741

14. Lehrer S, Rheinstein PH. Ivermectin docks to the SARS-CoV-2 spike receptor-binding domain attached to ACE2. In Vivo. 2020;34 (5):3023-3026. doi:10.21873/invivo.12134

15. Rodriguez-Morales AJ, Gallego V, Escalera-Antezana JP, et al. COVID-19 in Latin America: the implications of the first confirmed case in Brazil. Travel Med Infect Dis. 2020;35:101613. doi:10.1016/j. tmaid.2020.101613

16. Rodriguez-Morales AJ, Sánchez-Duque JA, Hernández-Botero S, et al. Preparación y control dela enfermedad por coronavirus 2019 (COVID-19) en América Latina. Acta Medica Peruana. 2020;37 (1):3-7. doi:10.35663/amp.2020.371.909

17. Gallego V, Nishiura H, Sah R, Rodriguez-Morales AJ. The COVID-19 outbreak and implications for the Tokyo 2020 Summer Olympic Games. Travel Med Infect Dis. 2020;2020:101604. doi:10.1016/j.tmaid.2020.101604

18. Abdelmaksoud AA, Ghweil AA, Hassan MH, et al. Olfactory disturbances as presenting manifestation among egyptian patients with COVID-19: possible role of zinc. Biol Trace Elem Res. 2021:1-8. doi:10.1007/s12011-020-02546-5

19. Wang YY, Jin YH, Ren XQ, et al. Updating the diagnostic criteria of COVID-19 "suspected case" and "confirmed case" is necessary. Mil Med Res. 2020;7(1):1-3. doi:10.1186/s40779-020-00245-9

20. Li L, Li R, Wu Z, et al. Therapeutic strategies for critically ill patients with COVID-19. Ann Intensive Care. 2020;10(1):45. doi:10.1186/s13613-02000661-z

21. Zhang J, Wang X, Jia X, et al. Risk factors for disease severity, unimprovement, and mortality in COVID-19 patients in Wuhan, China. Clin Microbiol Infect. 2020;26(6):767-772. doi:10.1016/j.cmi.2020.04.012

22. Ministry of Health and Population. Egyptian national guidelines for COVID-19. 2020. Available online: https://hiph.alexu.edu.eg/images/ egyptian_national_guidelines_covid-19.pdf. Accessed December 1, 2020

23. Xia D, Quan P, Piao H, et al. Preparation of stable nitrendipine nanosuspensions using the precipitation-ultrasonication method for enhancement of dissolution and oral bioavailability. Eur J Pharm Sci. 2010;40(4):325-334. doi:10.1016/j.ejps.2010.04.006

24. Hegazy AA, Hegazy RA. COVID-19: virology, pathogenesis and potential therapeutics. Afro-Egypt J Infect Endem Dis. 2020;10 (2):93-99. doi:10.21608/AEJI.2020.93432

25. Mastrangelo E, Pezzullo M, De Burghgraeve T, et al. Ivermectin is a potent inhibitor of flavivirus replication specifically targeting NS3 helicase activity: new prospects for an old drug. $J$ Antimicrob Chemother. 2012;67(8):1884-1894. doi:10.1093/jac/dks147

26. Lundberg L, Pinkham C, Baer A, et al. Nuclear import and export inhibitors alter capsid protein distribution in mammalian cells and reduce venezuelan equine encephalitis virus replication. Antiviral Res. 2013;100(3):662-672. doi:10.1016/j.antiviral.2013.10.004
27. Azeem S, Ashraf M, Rasheed MA, Anjum AA, Hameed R. Evaluation of cytotoxicity and antiviral activity of ivermectin against newcastle disease virus. Pak J Pharm Sci. 2015;28(2):597-602.

28. Jabeen T, Khader MA, Jabeen S. A review on the antiparasitic drug ivermectin for various viral infections and possibilities of using it for novel severe acute respiratory syndrome coronavirus 2: new hope to treat coronavirus disease-2019. Asian $J$ Pharm Clin Res. 2020;13:21-27. doi:10.22159/ajpcr.2020.v13i8.38357

29. Ghweil AA, Hassan MH, Khodeary A, et al. Characteristics, outcomes and indicators of severity for COVID- 19 among sample of ESNA Quarantine Hospital's Patients, Egypt: a retrospective study. Infect Drug Resist. 2020;13:2375-2383. doi:10.2147/IDR.S263489

30. Liu K, Chen Y, Lin R, Han K. Clinical features of COVID-19 in elderly patients: a comparison with young and middle-aged patients. $J$ Infect. 2020. doi:10.1016/j.jinf.2020.03.005

31. Mahase E. Covid-19: death rate is $0.66 \%$ and increases with age, study estimates. BMJ. 2020;369:m1327. doi:10.1136/bmj.m1327

32. Yang J, Zheng Y, Gou X, et al. Prevalence of comorbidities and its effects in patients infected with SARS-CoV-2: a systematic review and meta-analysis. Int $J$ Infect Dis. 2020;94:91-95. doi:10.1016/j. ijid.2020.03.017

33. Kumar S, Singh R, Kumari N, et al. Current understanding of the influence of environmental factors on SARS-CoV-2 transmission, persistence, and infectivity. Environ Sci Pollut Res Int. 2021;28 (6):6267-6288. doi:10.1007/s11356-020-12165-1

34. Aly MH, Rahman SS, Ahmed WA, et al. Indicators of critical illness and predictors of mortality in COVID-19 patients. Infect Drug Resist. 2020;13:1995-2000. doi:10.2147/IDR.S261159

35. Marhl M, Grubelnik V, Magdič M, Markovič R. Diabetes and metabolic syndrome as risk factors for COVID-19. Diabetes Metab Syndr. 2020;14(4):671-677. doi:10.1016/j.dsx.2020.05.013

36. Singh AK, Gupta R, Ghosh A, Misra A. Diabetes in COVID-19: prevalence, pathophysiology, prognosis and practical considerations. Diabetes Metab Syndr. 2020;14(4):303-310. doi:10.1016/j. dsx.2020.04.004

37. Shouman WM, Hegazy AA, Nafae RM, et al. Use of ivermectin as a potential chemoprophylaxis for COVID-19 in Egypt: a randomised clinical trial. J Clin Diagn Res. 2021. doi:10.7860/JCDR/2020/ 46795.0000

38. Alam MT, Murshed R, Bhiuyan E, Saber S, Alam R, Robin R. A case series of 100 COVID-19 positive patients treated with combination of ivermectin and doxycycline. J Bangladesh Coll Phys Surg. 2020;38:10-15. doi:10.3329/jbcps.v38i0.47512

39. Rajter JC, Sherman MS, Fatteh N, Vogel F, Sacks J, Rajter JJ. Use of ivermectin is associated with lower mortality in hospitalized patients with coronavirus disease 2019: the ivermectin in COVID nineteen study. Chest. 2021;159(1):85-92. doi:10.1016/j.chest.2020.10.009

40. Saindane NS, Pagar KP, Vavia PR. Nanosuspension based in situ gelling nasal spray of carvedilol: development, in vitro and in vivo characterization. Aaps Pharmscitech. 2013;14(1):189-199. doi:10.1208/s12249-012-9896-y

41. Errecalde J, Lifschitz A, Vecchioli G, et al. Safety and pharmacokinetic assessments of a novel ivermectin nasal spray formulation in a pig model. J Pharm Sci. 2021;110(6):2501-2507. doi:10.1016/j. xphs.2021.01.017 


\section{Publish your work in this journal}

The International Journal of Nanomedicine is an international, peerreviewed journal focusing on the application of nanotechnology in diagnostics, therapeutics, and drug delivery systems throughout the biomedical field. This journal is indexed on PubMed Central, MedLine, CAS, SciSearch ${ }^{\circledR}$, Current Contents ${ }^{\circledR} /$ Clinical Medicine,

Journal Citation Reports/Science Edition, EMBase, Scopus and the Elsevier Bibliographic databases. The manuscript management system is completely online and includes a very quick and fair peer-review system, which is all easy to use. Visit http://www.dovepress.com/ testimonials.php to read real quotes from published authors. 